\title{
Empirical selection of ground support for dynamic conditions using charting of support performance at Hamlet mine
}

\author{
P Mikula Mikula Geotechnics Pty Ltd, Australia \\ B Gebremedhin Gold Fields Australia Pty Ltd, Australia
}

\begin{abstract}
This paper demonstrates assessment of ground support dynamic performance, using charting of easily available mine site data, to provide guidance for support selection for dynamic conditions. The process is transparent and accessible to site engineers, and is described for the Hamlet gold mine in Australia. The process defines the relationships between three factors: the seismic event magnitude, the level of damage caused, and the installed ground support. The process is firmly based on the recorded history of these three factors at the mine.

Site geotechnical engineers need a simple yet defensible support selection method for seismic conditions that can be used with confidence. The aim is to enable selection of the appropriate ground support according to the expected or forecast level of seismic hazard. Empirical charting represents one way of bracketing the performance of particular ground support schemes in dynamic conditions. It assesses the past performance of the installed ground support, to provide guidelines for forward selection of support.

This approach has limitations and uncertainties which add to the scatter of the data points in the charts. However, the approach has the advantages of including the actual installed bolts, seismic events, site geology and support performance, making the results calibrated to, and applicable to, the mine. It also benefits by not requiring estimation of quantities, including the ground motion (peak particle velocity) at the location of a support element, the site effect, and the energy and load capacities of those elements during dynamic disturbances.

The empirical charts are not transferable between mine sites. It is hoped that the description of the methodology in this paper will encourage engineers to explore similar work for their sites, and gain better understanding of the in situ performance of their ground support under dynamic conditions.
\end{abstract}

Keywords: ground support system, dynamic, support selection, support performance, seismicity, empirical, mining

\section{Introduction}

Site geotechnical engineers working in hard rock mines subject to seismic disturbances need a simple yet defensible support selection method that can be used with confidence in seismic conditions. The empirical approach is one way to achieve this if the necessary historical performance data is available.

The seismic phenomena is itself complex in nature, and the interaction of seismic radiation with installed support and the surrounding rock mass only adds to the complexity. Further difficult aspects relate to the behaviour of the support components, individually and collectively, and to the site variables such as quality of installation.

Several deterministic and empirical approaches dealing with these issues have been developed, but all have limitations and assumptions. The empirical approach is pursued in this paper. It appeals because it bypasses several difficulties of other approaches, and has the advantages of including the actual installed bolts, seismic events, site geology and support performance in the mine, which makes the results calibrated to, and applicable to, the mine. 
It is critically important to be aware that empirical charts are not transferable between mines for the many reasons described in this paper. Therefore it is hoped that the description of the methodology in this paper will encourage engineers to explore similar work for their sites, and gain better understanding of the in situ performance of their ground support under dynamic conditions.

\section{Hamlet geomechanics}

\subsection{Summary of site environment}

Gold Fields Australia operates the Hamlet gold mine in the St Ives mining district near Kambalda, Western Australia. The Hamlet deposit is contained within the basalt-hosted Hamlet Shear, dipping at $70^{\circ}$ to the east. Intense foliation and lower strength rock mass are present at the contacts to the shear and for a few metres into hanging wall and footwall.

Significant seismicity at Hamlet occurs mainly in, or near, the ore zone. The seismic monitoring records indicate the largest seismic event causing damage was $M_{L} 2.1$ on 20 February 2016 ( $M_{L}$ is local magnitude defined as $0.516 \cdot \log$ (moment) -6 and is approximately comparable to Richter magnitude). Seismic hazard at the mine is primarily due to:

- High horizontal stress field, with the principal stress adversely orientated to major structure.

- Foliation structures at the contacts to the orebody which are potential seismic slip surfaces.

- A mining method that currently concentrates stresses in sill pillars and diminishing pillars.

Bulking and minor squeezing failures also develop due to slip along existing joint surfaces, especially foliation, and along new stress fractures. Unravelling may occur in development and stopes, especially in foliated walls. Unravelling ground has a tendency to fall away from behind the ground support. Undercut walls are vulnerable. Undercutting can be by design or by virtue of prior failures.

\subsection{Hamlet support schemes}

\subsubsection{Friction bolt scheme}

Where static support only is required, the base ground support scheme comprises friction bolts ( 3 or $2.4 \mathrm{~m}$ long, $47 \mathrm{~mm}$ diameter, $1.4 \mathrm{~m} \times 1.1 \mathrm{~m}$ pattern) with welded mesh (wire diameter $5.6 \mathrm{~mm}$, with $100 \mathrm{~mm}$ squares), and mesh overlap of 3 squares. Mesh coverage is back, shoulders and walls to within $2 \mathrm{~m}$ of the floor.

\subsubsection{Hybrid bolt scheme}

Where squeezing or seismic conditions apply, the above base scheme is typically enhanced by adding hybrid bolts ( $2.4 \mathrm{~m}$ long, $47 \mathrm{~mm}$ diameter, $1.4 \times 1.1 \mathrm{~m}$ pattern) as a Dice-5 pattern over the existing base scheme of friction bolts and mesh.

The hybrid bolt used at Hamlet is produced by Garock (Figure 1). The hybrid bolt comprises a central bar supported within a hollow tube with a conical mechanical anchor at the toe. Adjacent to the collar is a yield mechanism whereby under dynamic strain, the central bar is cold-drawn through a die. Recent in situ dynamic drop testing at Hamlet indicated that the bolt provided about $20 \mathrm{~kJ}$ energy dissipation over $200 \mathrm{~mm}$ displacement.

Other schemes used less frequently comprise the base scheme enhanced by one or more of mesh straps, aligned along or across a drive, as required; cable bolts, $15.2 \mathrm{~mm}$ diameter single or twin strand, bulbed, typically at $6 \mathrm{~m}$ length; and fibrecrete at a typical thickness of $50 \mathrm{~mm}, 28$ day strength greater than $32 \mathrm{MPa}$, usually applied in cycle before mesh installation. 


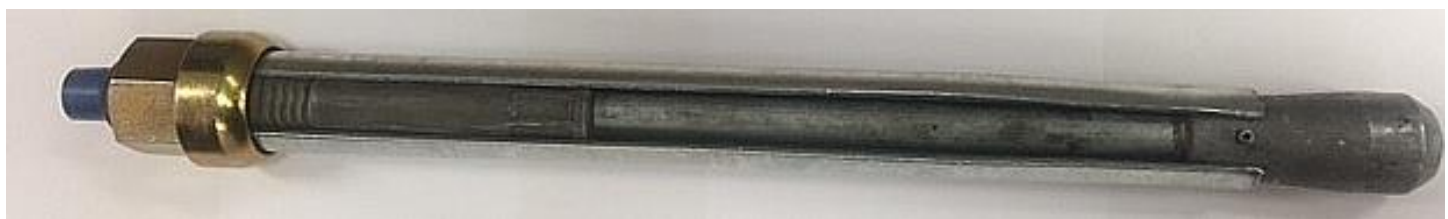

Figure 1 The Garock hybrid bolt supplied by Fero Strata Systems. A yielding mechanism is provided adjacent the collar, and a point anchoring cone arrangement at the toe of the unit

\subsection{Hamlet support system performance}

The typical damage mechanism in the mine, whether seismic or squeezing, is buckling and bulking of foliated rock mass material in the walls of the excavation (Figure 2). This imposes elongation onto the rockbolt elements, and stretching of the mesh. Major weak links are rings and plates popping off split sets, and mesh tearing from bolts at collars. Some hybrid bolts have been known to rupture, or to be enveloped by the squeezing rock mass after loss of the bearing plate (Figure 3 ).

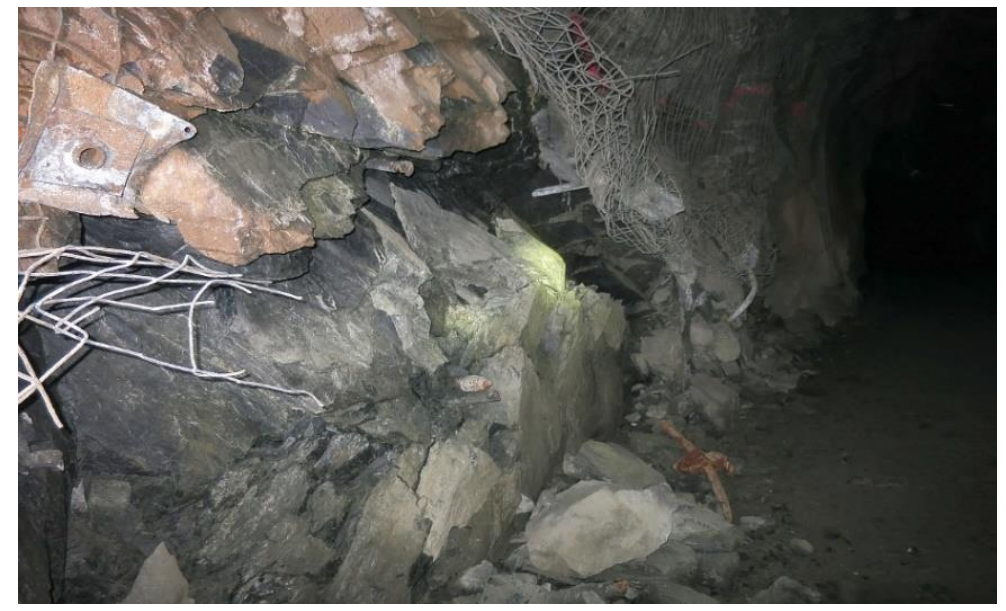

Figure 2 Example of bulking of the lower wall towards the excavation. The buckling action is facilitated by intense foliation surfaces dipping steeply towards the excavation

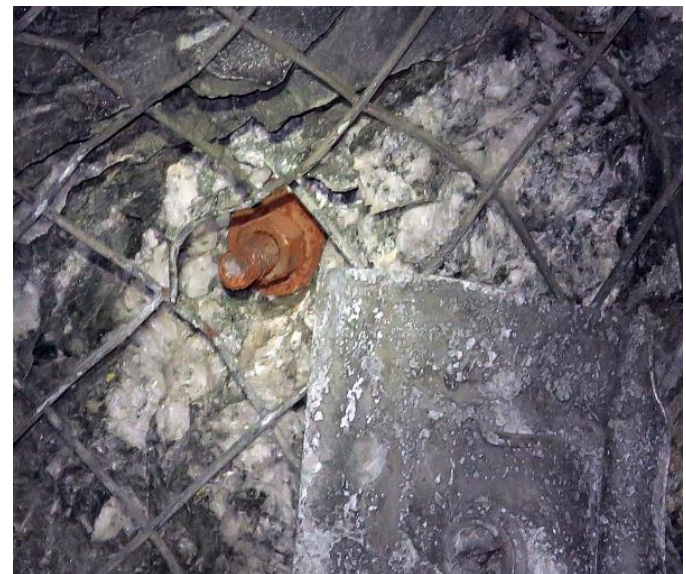

Figure 3 Example of a hybrid bolt that has lost its bearing plate and is being sucked into the rock mass

Where bolts or mesh failed, the amount of deformation due to a significant seismic event could be excessive and has reached $0.8 \mathrm{~m}$. Where bolts and mesh remained functional, bolt collar displacement was often in the order of $50 \mathrm{~mm}$ and bagging of mesh between bolts sometimes reached 300 to $500 \mathrm{~mm}$.

In access drives, ground support system failures occur more often on walls, dominantly in the lower walls below the mesh line, and partly extending up into the meshed parts of walls. Ground support in the backs performs adequately on most occasions. Falls of ground are usually a rill of broken material from the walls. 


\section{$3 \quad$ Philosophy of selection of ground support for dynamic conditions}

There are several approaches to the selection of appropriate dynamic ground support, but the task is complex. Solutions are provided only with a significant number of simplifying assumptions.

\subsection{Deterministic approaches}

The deterministic approaches include the Canadian Rockburst Support Handbook method, and the Kinetic \& Potential energy calculation method (Heal 2007; Kaiser et al. 1995; Scott et al. 2008). They make various assumptions about dynamic mechanisms in order to enable computation of support requirements.

There are difficulties with pursuing deterministic approaches to ground support selection for dynamic loading situations, due to the insufficient understanding of the controlling mechanics, and the lack of valid data to describe them. To the extent that the approaches do not match the unknowns and complexities, confidence in the results is reduced, which means that the approaches should be applied with awareness of their limitations.

As indicated by Stacey (2012), "the performance of support elements on an individual basis is rarely of much relevance, since it is the performance of the rock support system that is of importance." The complexities of dynamic support extend beyond just the energy capacity of a particular support element. A review of some of these aspects is included in Mikula (2012).

Stacey (2012) noted the complexities of the field and stated that "owing to these complex situations, theoretical determination of the capacity of a support system is very unlikely to be successful, particularly in a dynamic loading environment."

\subsection{Empirical approach - support performance charts}

An empirical approach is attractive, but it also has limitations and depends on assumptions as noted by Mikula (2012). The empirical method relies on site data, and when sufficient data is available, it becomes feasible to make a qualitative appraisal of the performance of the in situ support system.

The compilation of support performance charts relating event magnitude, ground support systems, and extent of damage has been explored for several Western Australian hard rock mines by Mikula and Lee (2007), and Mikula (2012). This work has also been presented at industry workshops (Mikula 2009, 2011). Observational data from four mines has been analysed to develop empirical relationships between three parameters:

- Incoming peak particle velocity (PPV) due to a seismic event.

- Installed ground support scheme (component types, condition, installed density).

- Degree of damage sustained by the ground support.

The first few applications of this method included the specific assessment of the dynamic load and energy dissipation capacities of the support schemes and, due to the assumptions required, it was difficult to have high confidence in the calculated capacities. Nevertheless, it was possible to develop simple practical guidelines for support selection. These were used with a high degree of success in the mines concerned, at one mine there were only two instances where the installed support failed to perform as well as expected under strong seismic loading.

This work, being based on empirical data, carries some uncertainty and invokes assumptions, but does provide a reasonable indication of ground support requirements in dynamic conditions. Work continues to refine the data and improve the confidence in the method. An attraction of this approach is that it bypasses many of the assumptions necessary for deterministic methods, so is simpler to apply.

The current application of this method differs from the previous ones, as it is simplified and does not include any assessment of the support scheme dynamic load and energy capacities at all. This varied approach is described below. 


\subsection{Other empirical approaches}

Various other empirical approaches have been developed. For example, Liang et al. (2011) presented a review of 90 rockburst incidents at Coleman and North mines, and used Principal Component Analysis and Partial Least Square projection to latent structures to study the relationship between support, damage location characteristics, and seismic event information. The type of information collected is similar to that involved in the Hamlet study, and the authors encountered similar difficulties in ensuring quality data was available. However at Hamlet, the project aim differs - rather than undertaking that type of statistical analysis, it is a direct charting of the dataset as described below.

An assessment method known as Excavation Vulnerability Potential (EVP) was presented by Heal et al. (2006). This is an empirical index that considers stress conditions, ground support, span, and geological structures to estimate the vulnerability of an excavation to dynamic disturbance. The method employs an estimate of the peak particle velocity (PPV) to represent the dynamic disturbance. The method does not include a historical dataset and does not assess the performance of the ground support in specific cases. Rather than specifically estimating ground support capacities, it applies a rating of 2, 5, 8, 10 or 25 to represent increasing energy absorption of the ground support scheme, as follows:

- 2 -spot bolting, no surface supported.

- 5 - pattern bolting (spacing 1 to $1.5 \mathrm{~m}$ ) with mesh or $50 \mathrm{~mm}$ fibrecrete.

- 8 - pattern bolting (spacing $<1 \mathrm{~m}$ ) with mesh or $50 \mathrm{~mm}$ fibrecrete.

- 10 - pattern bolting with mesh or $50 \mathrm{~mm}$ fibrecrete, plus pattern cable bolting.

- 25 - pattern dynamic support (dynamic bolts plus dynamic capable surface support system).

\section{$4 \quad$ Aim of empirical charting}

The aim of empirical charting is to provide site geotechnical engineers with support selection guidance that can be used confidently for dynamic conditions. Site engineers currently do not usually have the benefit of advanced computer models or of all the data needed to populate various analytical methods. Neither do they have a standardised way to estimate the dynamic support capacity of a support scheme.

Empirical charting represents one way of bracketing the performance of a particular ground support scheme in dynamic conditions. This enables selection of the appropriate ground support according to the expected or forecast level of seismic hazard.

This approach includes the actual installed bolts, seismic events, site geology and performance, making the results calibrated to, and applicable to, the mine. Input parameters are used to represent the following:

- The intensity of the seismic disturbance impacting a support element.

- The type of installed ground support scheme.

- The degree of damage sustained by the ground support.

Some of the attributes, advantages and difficulties of these parameters are now briefly reviewed.

\section{The task of estimating ground motion at a support element}

\subsection{Bypassing the estimation of a site effect factor}

The empirical approach requires an input parameter to represent the seismic disturbance. One such parameter could be the PPV that occurs at the surface of the excavation at the position of the ground support element. Unfortunately many factors complicate the estimation of a PPV at that position. Refer Mikula (2012) for a discussion of these. 
A difficult problem is related to the 'site effect'. Mendecki (2016) defined site effect as "a modification of ground motion in the time and in the frequency domain caused by local site conditions." In actual failures the ejection PPV at the position of the support is poorly related to the incoming PPV (i.e. the radiated PPV that theoretically would exist at that point in solid media, without the excavation, and without site effects, as attenuated by distance from the source). The site effect describes the difference, and represents the totality of the factors responsible for the difference.

Heal $(2007$, p.18) noted that it has been reported that "the ground motion in the fractured zone of rock around an excavation can be up to four to ten times larger than that in solid rock." The site effect is a variable or tensor, not a point value, depending on at least the complex wavelength and intensity package of the seismic disturbance, as well as the failure mechanism, thickness of failure zone, and degree of fracturing. It is effectively unknown unless measured. Mendecki (2016) provided some examples indicative of the complexity of its measurement. Given this situation, it is not usually feasible to know the actual ejection PPV, so it is not a useful parameter for either deterministic or empirical work.

In contrast, the incoming PPV can be estimated from the event magnitude and distance away, ideally using a strong ground motion relationship developed for the site, for example refer Potvin and Wesseloo (2013). Incoming PPV is available as a potential proxy parameter to represent the seismic disturbance. There is then no need to estimate a site effect factor. This was the approach adopted in previous work by Mikula and Lee (2007), and Mikula (2012).

\subsection{Bypassing identification of near field and far field}

The near field of a seismic event is the zone where the PPV is thought to be the highest as well as locally more variable. Therefore, it is reasonable to assume that the worst damage occurring due to an event is likely to be located close to the source of the seismic event, specifically in the near field of the event.

Recorded damage data will represent damage at a mixture of both near field and far field locations. A significant proportion of cases can reasonably be expected to be near field, and most importantly, represent challenging or worst case performance conditions for the ground support. This is an essential requirement for the empirical charting method which depends on inclusion of worst case data points.

The empirical charting method bypasses the need to identify which specific data points represent near field or far field conditions. It also avoids the need to estimate the size of the near field volume. It only requires some of the total pool of points to be from the near field.

\subsection{Bypassing PPV in favour of magnitude}

The approach in this paper was to adopt event magnitude rather than incoming PPV as the proxy parameter to represent the seismic disturbance. This is based on the above discussion on near field and far field, and the work of Heal (2007) and McGarr (1991).

Heal (2007) discussed the uncertainties in the calculation of near field PPV, and suggested an alternative approach of using a characteristic value of PPV based on the largest expected event magnitude. Heal wrote that, "Rather than employing complex models to define PPV in the near-field, McGarr (1991) proposed that for the magnitude range of mining induced seismic events, there is an approximately linear relationship between event magnitude and ground motion close to the source. This was based on estimates of underground damage due to a range of near-fault ground velocities at a number of mines."

Because magnitude, rather than PPV, is used in this approach, error in the location of the event hypocentre is irrelevant. That error, in other methods, leads to miscalculation of the distance between the hypocentre and the damage, with potential misallocation of damage between near and far field, and miscalculation of PPV at the damage location.

A caution accompanying the magnitude parameter is the potential existence of magnitude scale deficiencies. The higher magnitudes may saturate if the seismic sensor array in the mine is deficient, i.e. the recorded 
magnitudes may be less than the actual magnitudes. This would cause a certain level of damage to be associated with a lesser magnitude of event in the chart. However, this is a conservative error and as such is tolerable. However, it is another reason why the chart is only applicable for the specific mine for which it is generated, and is not portable between mines.

\subsection{Displacement and strain alternatives to PPV}

The dominant frequency of a seismic disturbance is crucial. It is known that for a given intensity of disturbance, lower frequency vibrations are more damaging. In part, this is because lower frequencies, or longer wavelengths, allow greater strains and distortions of the rock mass to occur, with higher probability of damage occurring.

For that reason, a representation of the strain, or displacement, could be considered as an input parameter for this type of empirical work. Using McGarr's observation above for the relationship between magnitude and ground motion close to the source (i.e. near field), and the simplification (for regular sinusoidal motion) that displacement is a function of vibration intensity (PPV) divided by frequency, one such representative, or proxy parameter, is magnitude divided by vibration frequency. This approach is a consideration for future work.

\section{The task of estimating capacity of the installed support}

As alluded to earlier by Stacey (2012), engineers do not have the means to truly know in situ energy or load capacity of a support scheme in dynamic ground. Determining that capacity is a very complex area, being difficult to test, both in laboratory and field. Many variables influence dynamic performance, including rate of loading, duration of loading, intensity of loading, variable quality of installations, imperfections in the ground support element, type of anchorage, borehole-rock interface, and even the type of instrumentation used to measure the performance. Some of the problems are now described.

\subsection{Drop tests}

While laboratory drop tests are certainly welcome and necessary, and give a means to compare various elements, as well as provide some guidance towards likely in situ performance, they are not in situ tests. They do not test bolts in actual conditions, nor do they apply a dynamic disturbance that simulates actual disturbances. Rocktech, Fero Strata Systems and Sandvik Mining have introduced drop test rigs capable of conducting in situ tests, which unsurprisingly provides different results for certain bolts compared to laboratory drop tests. There are probably numerous factors accounting for the differences.

\subsection{Limited test standards}

It has happened more than once, where the same group of installed bolts was independently statically proof load tested by two different service providers, and the results were significantly different. A brief review of the proof load procedures used by different operators will usually reveal differences between them, and reveal that the procedures are not necessarily followed. Presently, there is a test standard for laboratory static and dynamic testing (ASTM International 2008) but that standard is limited, does not cover all test aspects, and does not apply in situ.

\subsection{Ground support consumed capacity}

The empirical approach ideally would use the ground support consumed capacity of a particular element as one input parameter. In practice, deriving that parameter is very labour intensive. Complications include the degrading effect of multiple seismic hits, installation problems, corrosion problems, and rock mass movements, such as shearing, which may compromise the bolt. The effect of this is to produce scatter in the data representing element performance for each instance of damage.

However, the existence of consumed capacity may be accounted for in an overall sense in the empirical charting, because some chart data points are likely to represent elements with a greater degree of consumed 
capacity at the time of the seismic disturbance. Damage at the location of those elements could then be worse. An example of this is likely for the Hamlet chart as described below.

\subsection{Scheme capacity is not the sum of its parts}

It is not valid to simply add, or superimpose, the various capacities supplied by bolt distributors. The rock mass and support together form a complex composite system. The stiffness of all components must be appropriate for the displacement that could be imposed on them during a dynamic disturbance. That displacement, however, is a function of the installed support, the rock mass and the dynamic disturbance, and cannot be predicted. This problem is not trivial. It indicates that in situ rather than laboratory approaches will have to be part of the solution.

\subsection{Scheme capacity is affected by weak links}

Weak links occur for a multitude of reasons, and a common experience is mesh tearing away from bolt collars. Western Australian School of Mines testing (Villaescusa et al. 2013) of numerous meshes has shown that most mesh surface support types have capacity much less than that of the bolt reinforcement system. The exceptions are the high strength chain link meshes. This weak link must be mitigated by strategies such as controlling mesh overlaps, using mesh with extra strands or chain link construction, and using closer bolting patterns. Some weldmesh designs, with internal strengthening, are now available and have performed better than conventional weldmesh in mitigating seismic damage underground.

\subsection{Relative stiffness and density of components}

A complex web of interactions exists between, and among, the various ground support components and the rock mass. For example, for a certain deformation, different bolts may share load as a function of their stiffness. However, for the interaction of bolt element stiffness and surface mesh stiffness, the lower stiffness component may take a greater share of the load (also depending on bolt density, and prior to the failure of the weakest link). In some situations, it was observed that the mesh stiffness was low, the mesh was loaded to failure, and the directly adjacent bolts did relatively little work. Had the surface support been stiffer (hypothetically, fibrecrete for example) then a greater proportion of the dynamic load would have been transferred to the bolts.

\subsection{Difference between load and energy demand}

The load demand on bolt elements is a function of imposed strain and strain rate. The energy demand on bolts is a function of potential or kinetic energy associated with a failing section of rock mass. A final static load demand also exists. These need not be in proportion to each other in any particular case. Scheme capacities must take all into account.

\section{$7 \quad$ Bypassing the need to compute support capacities}

Considering the types of complexities involved in estimating support capacities for dynamic situations, it is appropriate to explore ways of bypassing that task. The empirical chart method as used in earlier versions included estimation of these capacities. The work for Hamlet mine has developed a simplified chart that does not require those capacities to be estimated. Instead, it assumes the capacities applying at any one damage site are representative of the capacities elsewhere in the mine (for the same ground support scheme). Then it becomes sufficient to only identify the type of scheme that is installed.

This simplification is also a restriction, being only valid for the mine concerned and the support systems for which data is available. 


\section{The task of defining the damage sustained by ground support}

The details of ground support damage sustained during a seismic disturbance are unique in every instance, so it is necessary to adopt a more general method of describing support damage. The general method is required to be rapid to use and visual based. A key requirement is that it must be meaningful to site personnel, who need to make decisions about whether damage is minor or major, or whether repair and rehabilitation is required.

To meet these requirements, the six well known damage ratings described by Kaiser et al. (1995) are used as a starting point, and are adapted to take on the function of qualitative performance indicators, specific to the needs of the empirical charting (Table 1 ).

Table 1 Support Damage Scale rating summary guidelines for damage caused by a seismic event, modified from Kaiser et al. (1995), with performance indicators

\begin{tabular}{ll|l}
\hline Rating & Steel support damage guideline & Performance level \\
\hline S0 & No damage & Acceptable \\
\hline S1 & First signs of distress & Acceptable \\
\hline S2 & Loaded, plates deformed, mesh bagged but functional & Acceptable \\
\hline S3 & Heavy loaded, few broken, mesh bagged, some torn/open & Tolerable \\
\hline S4 & $\begin{array}{l}\text { Major damage, broken bolts, mesh failed or bagged to capacity, } \\
\text { rock ejected }\end{array}$ & Intolerable \\
\hline S5 & Complete failure of support components & Intolerable \\
\hline
\end{tabular}

The performance indicators for the ground support as follows:

- Damage classes S0 to S2 are regarded as acceptable, meaning that while the disturbance does work on the support, the disturbance does not compromise the functionality of the ground support, so that production may continue uninterrupted.

- Damage class S3 is regarded as tolerable, meaning that the ground support does require some repair, rehabilitation or replacement, but the extent of damage does not present a major threat to personnel or equipment. Support prevents fall of ground (other than small scats through mesh). Some production interruption may occur.

- Damage classes S4 to S5 are regarded as intolerable, meaning that the safety of personnel and equipment is compromised, and production is significantly impacted. Support has lost functionality to the point that a fall of ground has occurred.

Currently, the distinction between acceptable (S2) and tolerable (S3) performance is a site-based qualitative engineering judgement based on observations such as whether or not bolts were broken, whether or not mesh was bagged to capacity, and whether or not bolt bearing plates were heavily loaded.

\section{$9 \quad$ Data collection and conditioning}

The process involved collection of observational data on how ground support has performed under the seismic hits that have occurred in the mine since 2015. This data relates to the real installed bolts, the real seismic events, the real site geology, and the real performance. The results are therefore applicable to, or calibrated to, this specific mine.

Data available represented 67 separate damage observations arising from 31 seismic events. Some cases were observations of zero damage. Some events had multiple damage sites. The data set included 25 events of $M_{L} 1.0$ or more, and several smaller events for which the required data could be extracted. More 
observations are expected to be added as they become available over time. The greater the number of observations, the greater the confidence in the results of the process.

Each data point is linked to whichever one of the various ground support schemes was installed at the site of damage. The subset of useful data comprised 57 points, representing only two of the schemes: 32 for the friction bolt scheme and 25 for the hybrid bolt scheme. The following data points were discarded:

- 4 points for other schemes represented by only one data damage point.

- 5 points for the friction bolt scheme with uncertain data for which either the causal event or the damage could not be identified.

- 1 point for the hybrid bolt scheme with uncertain data for the same reason mentioned above.

Inherent variability exists between instances of a particular ground support scheme in attributes such as bolt length, spacing, anchorage, installation quality, and the geomechanical details of the rock mass. The variability is contained in the data and contributes to the scatter in the data.

Inherent variability also exists between seismic disturbances that happen to be recorded as having identical magnitudes. They will not be identical in other attributes, and this also contributes to scatter of data on the charts.

It is therefore necessary to define a lower-bound envelope to the data points. This envelope is intended to define the most adverse combinations of attributes, such as the cases where ground support installation quality was lacking, where some capacity was consumed prior to the seismic disturbance, or where an event of a given magnitude resulted in a particularly intense disturbance.

\section{The Hamlet dynamic support performance chart}

The data points are plotted in Figure 4 with magnitude as the $x$-axis. Where multiple data points happened to be superimposed, they were allocated small perturbations in the $y$-axis value to enable them to be clearly visible in the chart.

The lower bound (worst case, or minimum performance) envelope lines are shown on the chart for the two support schemes. Straight lines are used arbitrarily, on account of sparse data and lack of guidance on this aspect. The chart trend lines show that:

- Events below M 0.7 are not known to have damaged ground support.

- Performance of the friction bolt scheme is acceptable up to at least $M\llcorner 1.0$ and tolerable up to at least $M\llcorner$ 1.3. The term 'at least' indicates that the nominated magnitudes are considered to be worst case, pending further data coming to hand.

- Performance of the hybrid bolt scheme is acceptable up to at least $M_{L} 1.5$ and tolerable up to at least $M\llcorner$ 1.6. The term 'at least' indicates that the nominated magnitudes are considered to be worst case, pending further data coming to hand.

One anomalous friction bolt scheme data point is present in the chart, to the left of the denoted minimum performance envelope. This point is considered to represent a location where anecdotal reports indicated nearly all the support capacity had been consumed by squeezing ground movements prior to the seismic disturbance. It is not possible to verify this conclusion, and so the point should remain in the chart.

Performance of the hybrid bolt scheme is rated as intolerable multiple times for events of $M_{\llcorner} 1.8$ or more, causing the performance envelope line to be quite steep. On investigation, the cause of this was attributed to early failure of the bolt bearing plates, or to tearing of mesh away from hybrid bolt collars, while the bolts themselves remained intact. In that sense, the hybrid and friction bolt schemes have similar performance during the more intense seismic disturbances. Since then the bearing plates and mesh have been strengthened, and it is expected that a new data group showing improved hybrid bolt performance will become available over time. 


\section{Hamlet - Dynamic Ground Support Performance Chart}

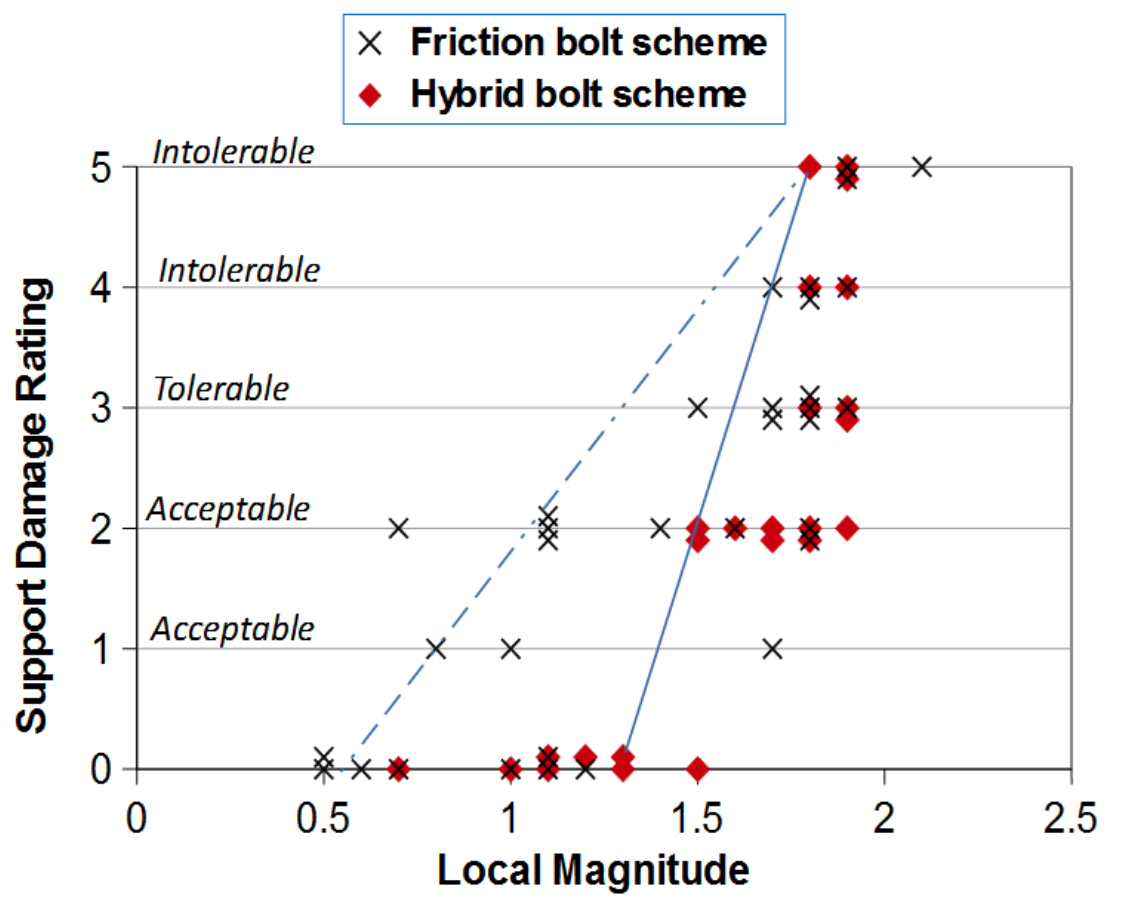

Figure 4 Support Performance Chart - Hamlet. Dashed line $=$ friction bolt scheme minimum performance. Solid line $=$ hybrid bolt scheme minimum performance. The Performance Indicators of Acceptable, Tolerable or Intolerable are shown

\section{Using the chart for forward design}

To use the chart in Figure 4 for forward design, i.e. for selection of an appropriate support scheme, it is necessary to estimate an expected largest event magnitude that may occur in a given location. However that estimation is outside of the scope of this paper. These estimates can be conducted in various ways, but essentially they are obtained from site seismic history for the area together with some means of estimating the next highest event expected.

At present, the chart is only applicable to the two support schemes in use at the mine. If the mine adopts alternative schemes, then future performance data will be used to expand the chart to include those schemes. The use of any bolt type in seismic conditions is subject to a design review to ensure their suitability for conditions in the areas they are to be used. The chart is reviewed and updated periodically, as new data becomes available.

\section{Concluding remarks}

The empirical approach to ground support selection for dynamic situations overcomes some of the difficulties of the deterministic approaches. It avoids the need to consider parameters which can be difficult to estimate or define, including the PPV at the location of a support element, the site effect, the distinction between near field and far field, the error in computation of event hypocentres, and the energy and load capacities of elements during dynamic disturbances.

However, it also has limitations and assumptions, and it relies on site data which is often imprecise. Scatter of data points in the charts exists for reasons including magnitude scale deficiencies, variability of ground support installation, and the consumed capacity of ground support components.

The charting process is transparent - the imprecision is clearly indicated on the chart. The greater the number of observations, the greater the confidence in the results of the process. 
Site geotechnical engineers need a simple, yet defensible, support selection method that can be used with confidence. The empirical approach is one way to provide this. The method is easy to apply on mine sites. It only requires collection of data on event magnitudes, damage caused, and the installed ground support scheme. Because it involves the actual installed bolts, seismic events, site geology and performance, the results are calibrated to, and applicable to, the mine.

It is critically important to be aware that the charts are not transferable between mines for the many reasons described in this paper.

It is hoped that the description of the methodology in this paper will encourage engineers to explore similar work for their sites, and gain better understanding of the in situ performance of their ground support under dynamic conditions.

\section{Acknowledgement}

The authors express their appreciation to Claire Dyson, who first put pen to paper to create the prototype of the empirical chart in this paper. Many thanks to Belay Gebremedhin, who spent much time underground collecting the required data. The authors gratefully acknowledge the Hamlet mine management, for enabling this work to proceed, and Gold Fields Australia, for permission to publish this paper.

\section{References}

ASTM International 2008, Standard Test Methods for Laboratory Determination of Rock Anchor Capacities by Pull and Drop Tests, Designation D7401 - 08, ASTM International, West Conshohocken, Pennsylvania, pp. 7.

Heal, D 2007, 'Ground support for rockbursting conditions - Theory and Practice', Section 5, Advanced Ground Support in Underground Mining Course, presented by Australian Centre for Geomechanics, Perth, Western Australia, Course No. 0703.

Heal, D, Potvin, Y \& Hudyma, M 2006, 'Evaluating rockburst damage potential in underground mining', in DP Yale, SC Holtz, C Breeds \& U Ozbay (eds), Proceedings of the 41st US Symposium on Rock Mechanics, ref. no. ARMA/USRMS $06-1020$, American Rock Mechanics Association, Alexandria, Virginia.

Kaiser, PK, McCreath, DR \& Tannant, DD 1995, Canadian Rockburst Support Handbook, Geomechanics Research Centre, Laurentian University, Sudbury, Ontario.

Liang, G, Hadjigeorgiou, J \& Thibodeau, D 2011, 'Evaluation of Performance of support systems at Vale's Coleman and North Mine', in A Innacchione, G Esterhuizen \& A Tutuncu (eds), Proceedings of the 45th US Rock Mechanics/Geomechanics Symposium, ref. no. ARMA 11-289, 26-29 June 2011, San Francisco, California, American Rock Mechanics Association, Alexandria, Virginia.

McGarr, A 1991, 'Observations constraining near-source ground motion estimated from locally recorded seismograms,' Journal of Geophysical Research, vol. 96, no B10, pp. 16495-16508.

Mendecki, A 2016, Mine Seismology Reference Book - Seismic Hazard, Institute of Mine Seismology, pp. 88.

Mikula, PA 2009, Dynamic Ground Support Selection Chart for Longshaft Nickel Mine, Eastern Australian Ground Control Group meeting presentation, May 2009.

Mikula, PA 2011, Selection of Dynamic Ground Support - Progress in Empirical Charting, presentation to Mining Initiative for Development of Ground Support Systems and Equipment (MIGS), Workshop WP10 on Usefulness of Seismic Systems for Decisions on Mine Design and Mine Operation.

Mikula, PA 2012, 'Progress with empirical performance charting for confident selection of ground support in seismic conditions', in Y Potvin (ed), Proceedings of the Sixth International Seminar on Deep and High Stress Mining, 28-30 March 2012, Perth, Western Australia, Australian Centre for Geomechanics, Perth, Western Australia, pp. 71-89. Also published as Mikula, PA 2012, 'Progress with empirical performance charting for confident selection of ground support in seismic conditions', Mining Technology, vol. 121, no. 4, pp. 192-203.

Mikula, PA \& Lee, MF 2007, 'Empirical performance chart for ground support in seismic conditions at Mt Charlotte', in Y Potvin (ed.), Proceedings of the Fourth International Seminar on Deep and High Stress Mining, Australian Centre for Geomechanics, Perth, Western Australia, pp. 325-334.

Potvin, Y \& Wesseloo, J 2013, 'Towards an understanding of dynamic demand on ground support', Journal of the Southern African Institute of Mining \& Metallurgy, vol. 113, December 2013, pp. 913-922.

Scott, C, Penney, AR, Fuller, P 2008, 'Competing Factors in Support Selection for the West Zone of the Beaconsfiled Gold Mine, Tasmania', in S Dominy (ed), Proceedings of the Narrow Vein Mining Conference 2008, 14-15 October 2008, Ballarat, Australian Institute of Mining and Metallurgy, Carlton South, Victoria, pp. 173-178.

Stacey, TR 2012, 'A philosophical view of the testing of rock support for rockburst conditions', Journal of the Southern African Institute of Mining \& Metallurgy, vol. 112, August 2012, pp. 703-710.

Villaescusa, E, Thompson, AG \& Player, JR 2013, 'Static and Dynamic Testing of Welded and Woven Mesh for Rock Support', in Y Potvin \& B Brady (ed), Proceedings of the Seventh International Symposium on Ground Support in Mining and Civil and Engineering Construction, Australian Centre for Geomechanics, Perth, Western Australia, pp. 187-196. 